American Journal of Pharmaceutical Education 2019; 83 (5) Article 6764.

\title{
RESEARCH
}

\section{Addressing Unmet Patient Care Needs Through Curricular Development of Student Pharmacist Leadership and Entrepreneurial Skills}

\author{
Shannon G. Panther, PharmD, ${ }^{a}$ Rachel A. Allen, PharmD, ${ }^{b}$ Kelsey Brantner, BS, ${ }^{b}$ Curtis G. Jefferson, EdD, \\ Nanci L. Murphy, PharmD, ${ }^{b}$ Jennifer D. Robinson, PharmD ${ }^{c}$ \\ ${ }^{\text {a }}$ Kaiser Permanente Washington, Seattle, Washington \\ ${ }^{\mathrm{b}}$ University of Washington School of Pharmacy, Seattle, Washington \\ ${ }^{\mathrm{c}}$ Washington State College of Pharmacy, Spokane, Washington
}

Submitted August 29, 2017; accepted December 21, 2017; published June 2019.

Objective. To develop, deliver, and evaluate an innovative curriculum designed to increase student pharmacists' skills and confidence in addressing unmet patient care needs and the Institute for Healthcare Improvement's (IHI) Triple Aim goals in the community pharmacy setting.

Methods. Course modules developed collaboratively between the University of Washington and Washington State University focused on student pharmacist exposure to and direct application of leadership theory in addressing real world challenges. Both programs delivered the curriculum to all second-year student pharmacists during the fall 2015 and fall 2016 semesters. Student teams were asked to identify a new or enhanced service for a community pharmacy based on a needs assessment and the IHI's Triple Aim goals. Students completed precourse, postcourse, and retrospective assessments of their confidence, comfort level in leadership theory application, and project implementation. Effectiveness of the project pitch and team dynamics were assessed. Precourse, postcourse, and retrospective assessments of individual student progress in leadership, innovation, self-awareness, and professionalism also were completed.

Results. For all confidence questions, a significant relationship was found between mean precourse and postcourse scores. A comparison of students' postcourse scores and their retrospective reflection scores indicated an increase in confidence to lead. At the conclusion of the course, the students reported improved confidence in their ability to communicate decisions (73\%), create a vision (64\%), and form a guiding coalition (55\%).

Conclusion. A five-module curriculum with corresponding project proposal successfully increased the confidence and comfort level of student pharmacists' in their leadership skillset.

Keywords: leadership, self-directed learning, instructional design, teamwork, innovation

\section{INTRODUCTION}

Fostering the growth of competent leaders and change agents is critical to address existing and future challenges to the US health care system. ${ }^{1}$ Community pharmacists are well-positioned to help achieve the Triple Aim goals of the Institute for Healthcare Improvement (IHI) by increasing access to health care services, improving the quality of the patient care experience (patient outcomes and satisfaction), and reducing unnecessary costs through health promotion, early detection of disease, and better chronic disease state management. ${ }^{2,3}$

While pharmacists are in a unique position to address many of the challenges present in our communities, espe-

Corresponding Author: Shannon G. Panther, Kaiser Permanente Washington, 125 16th Ave. E, Seattle, WA 98112. Tel: 425-248-0051.E-mail: Panther.s@ghc.org. cially those that are medically underserved, the potential for pharmacists to meet these needs has not been fully realized. There are many reasons why the profession has not fully recognized its potential to meet health care needs that are still unmet, eg, current practice laws, the reimbursement model for pharmacy services, a lack of leadership development, and not knowing how to effectively generate practice transformation are several potential factors. The focus of this paper is on the importance of developing leadership skills in students and inspiring student pharmacists to be agents of change.

A potential approach to address the need is to introduce, integrate, and apply a change management process to pharmacy service implementation in the Doctor of Pharmacy (PharmD) curriculum. By learning and applying skills through various stages of the change process, student pharmacists can begin to address public health needs. 


\section{American Journal of Pharmaceutical Education 2019; 83 (5) Article 6764.}

To be of high educational value, student pharmacists should be exposed to proven theories that have been used to support entrepreneurial change. ${ }^{4}$

The overarching goal of this collaborative leadership curriculum is to provide all student pharmacists currently enrolled in PharmD programs in Washington State the opportunity to develop the key competencies needed to innovate and advance pharmacy practice based on the following themes: leadership-develop high-impact skills as frontline leaders and contribute to positive change; strengths: identify personal strengths and learn how to develop and capitalize on strengths both in themselves and in others; teamwork: collaborate with others to achieve shared goals with structured tools and opportunities for reflection and feedback; real world applicationcreate an authentic leadership experience in developing or enhancing a patient care service in a community pharmacy setting.

\section{METHODS}

This research was reviewed by the respective institutional review board and classified as exempt at Washington State University (WSU) and approved at the University of Washington (UW). The UW and WSU collaborated to successfully design a curriculum focused on developing student pharmacist leadership and entrepreneurial skills. Because the programs had different academic calendars (semester and quarter systems), the institutions used an asynchronous course delivery format. To ensure equitable delivery of the material to the two institutions, the course instructors held a biweekly conference call to plan each module. Thus, WSU taught the material approximately one month before UW. After each module of the curriculum was delivered, the course instructors would debrief the students. The curriculum was implemented for the first time in the fall term of 2015 and delivered again to another cohort of students in the fall of 2016.

The curricular outcomes for the curriculum were aligned with the ACPE Standards 2016. ${ }^{5}$ The learning objectives described specific and measurable outcomes along with activities that best met these objectives. Participating faculty members used multiple teaching approaches with an instructional design that followed Fink's Taxonomy and Kolb's experiential learning theory. ${ }^{6,7}$ Assignments were strategically developed to support the desired level of learning and to actively engage all students. ${ }^{6,7}$ The leadership curriculum was divided into five modules that were delivered over 10 weeks, allowing for dedicated classroom time to cover the module content every other week. Each module consisted of 50 minutes or less of classroom contact time. The every other week design allowed for out-of-class "homework" time and group project development. Classroom time was used to introduce the topic for each module, put the material into context, and highlight the details of homework assignments. As the course progressed and the need for extensive classroom instruction decreased, more time was devoted to team discussions. The learning objectives, learning activities, and mapping to ACPE Standards for each module are described in Table $1 .{ }^{5}$

Throughout the five modules, students were asked to create a Clinical Community Pharmacy Project (CCPP) proposal and pitch. The intent of the project was for students to use knowledge gained during the community introductory pharmacy practice experience (IPPE) to create, develop, and outline the measures necessary for implementation of a new or enhanced clinical pharmacy service that would advance the practice of pharmacy while meeting one or more of the IHI's Triple Aim goals. A project guide was used longitudinally to assist students in creating their CCPP proposal (https://communitypharmacyfoundation.org/grants/grants_list_details.asp? grants_id=71006). The challenge-based learning model was modified for the project proposal guide in order to to give a structured method for creative problem-solving, allowing for team collaboration, and to serve as a platform for coming up with solutions to real-world problems. ${ }^{8}$ The project proposal guide required students to perform a needs assessment, develop a vision, identify how the proposal met at least one of the Triple Aim goals, recognize potential barriers and solutions to those barriers, outline the steps necessary for implementation and sustainability, and develop appropriate program evaluation measures. Self-selected teams (four students per team at UW and seven students per team at WSU) worked collaboratively on the CCPP. Each team had full autonomy over the project idea they would ultimately pursue.

To create an authentic experience, student pharmacist groups were tasked with not only creating a proposal to pitch, but also ensuring the services could truly be implemented in a community pharmacy setting. Selected project proposals with the potential to effect change, that could be easily implemented, and included a plan for sustainability were awarded "mini-grant" funding from the Community Pharmacy Foundation to assist with the start-up costs of their project. Supporting this endeavor, community pharmacists volunteered as practice partners for this curriculum by providing insight about the business structure of their practice, current services provided, general patient demographics, and identified specific patient-centered clinical needs. These community pharmacist practice partners were sought 


\section{American Journal of Pharmaceutical Education 2019; 83 (5) Article 6764.}

Table 1. Curriculum Map of a Community Pharmacy Curriculum Designed to Develop Student Pharmacist Leadership and Entrepreneurial Skills in Addressing Unmet Patient Care Needs

\begin{tabular}{|c|c|c|c|}
\hline & Seminar \& Assignments & Learning Objectives & $\begin{array}{c}\mathrm{ACPE} \\
\text { Standards }\end{array}$ \\
\hline $\begin{array}{l}\text { Module } 1 \text {. The state of health } \\
\text { care and future of } \\
\text { pharmacy practice in the } \\
\text { United States }\end{array}$ & $\begin{array}{l}\text { Seminar } \\
\text { Introduce foundations of the } \\
\text { course: leadership, strengths, } \\
\text { teamwork, and application in } \\
\text { community pharmacy practice } \\
\text { Introduce CCPP \& pharmacy } \\
\text { partners } \\
\text { Watch videos from RADM Scott } \\
\text { Giberson and APhA CEO Tom } \\
\text { Menighan } \\
\text { Assignments } \\
\text { Report to US Surgeon General } \\
\text { IHI assignment } \\
\text { CCPP guide parts 1-3 }\end{array}$ & $\begin{array}{l}\text { Recognize leadership occurs regardless } \\
\text { of title } \\
\text { Describe characteristics, behaviors, and } \\
\text { practices of effective health care } \\
\text { leaders } \\
\text { Identify the demands on US health care } \\
\text { delivery } \\
\text { Describe the pharmacist's role in } \\
\text { meeting the health care challenges in } \\
\text { the US } \\
\text { Determine the professional } \\
\text { development steps pharmacists } \\
\text { require to meet the changing health } \\
\text { care delivery model } \\
\text { Describe the IHI Triple Aim Goals } \\
\text { Identify the Triple Aim Goal(s) to be } \\
\text { achieved through implementation of a } \\
\text { new/enhanced clinical service in the } \\
\text { community pharmacy setting }\end{array}$ & $1.1,4.1,4.2$ \\
\hline $\begin{array}{l}\text { Module } 2 \text {. Determining } \\
\text { personal strengths to aid in } \\
\text { creating change }\end{array}$ & $\begin{array}{l}\text { Seminar } \\
\text { Strengths assessment introduction } \\
\text { Kotter's } 8 \text { steps for leading change } \\
\text { Assignments } \\
\text { Personal strengths assessment } \\
\text { Personal strengths reflection } \\
\text { CCPP guide part } 4\end{array}$ & $\begin{array}{l}\text { Reflect on your personal strengths and } \\
\text { identify how these strengths are } \\
\text { beneficial to yourself and others } \\
\text { Analyze how your personal strengths } \\
\text { could be a liability when working } \\
\text { independently and in a group } \\
\text { Review your top strength themes and } \\
\text { determine which action you are most } \\
\text { likely to take for each strength theme } \\
\text { Determine how you will use your } \\
\text { strengths to contribute effectively to a } \\
\text { team when working on a team project }\end{array}$ & $3.6,4.1,4.2,4.4$ \\
\hline $\begin{array}{l}\text { Module 4. Maximizing team } \\
\text { strengths to complete work } \\
\text { and understand how to } \\
\text { pitch your idea }\end{array}$ & $\begin{array}{l}\text { Seminar } \\
\text { Review rubric \& questions for } \\
\text { project pitch } \\
\text { In-class project preparation time } \\
\text { Assignments } \\
\text { CCPP pitch presentation }\end{array}$ & $\begin{array}{l}\text { Develop an organized and collaborative } \\
\text { approach to delivering your project } \\
\text { pitch with team members }\end{array}$ & $4.1,4.2,4.4$ \\
\hline
\end{tabular}


American Journal of Pharmaceutical Education 2019; 83 (5) Article 6764.

Table 1. (Continued)

\begin{tabular}{|c|c|c|c|}
\hline & Seminar \& Assignments & Learning Objectives & $\begin{array}{c}\text { ACPE } \\
\text { Standards }\end{array}$ \\
\hline $\begin{array}{l}\text { Module } 5 . \text { Pitch your idea to } \\
\text { stakeholders }\end{array}$ & $\begin{array}{l}\text { Seminar } \\
\text { Five-minute project pitch delivered } \\
\text { to classmates, faculty, and } \\
\text { pharmacy partners } \\
\text { Presentations evaluated in real-time } \\
\text { Assignments } \\
\text { Team member evaluation }\end{array}$ & $\begin{array}{l}\text { Present and defend a project proposal } \\
\text { developed to benefit patients, } \\
\text { pharmacists, and the pharmacy } \\
\text { Report the need and outline the benefits } \\
\text { that your service provides } \\
\text { Recommend an implementation plan for } \\
\text { the team's new/enhanced clinical } \\
\text { service } \\
\text { Demonstrate persuasive and succinct } \\
\text { communication strategies as part of a } \\
\text { project pitch } \\
\text { Deliver the project pitch with an } \\
\text { organized, collaborative, and } \\
\text { professional approach }\end{array}$ & $\begin{array}{l}1.1,2.3,2.4,3.1 \\
3.2,3.3,3.5,3.6 \\
4.1,4.2,4.3,4.4\end{array}$ \\
\hline
\end{tabular}

$\mathrm{CCPP}=$ Clinical Community Pharmacy Project

out as partners for a variety of reasons, such as having a track record of innovation at their practice site, being engaged in professional organizations, being a supportive and experienced preceptor, or being knowledgeable in a process for enhancing current or developing new services. Some community sites also agreed to provide the student groups with a potential avenue for implementation of innovative service ideas following the conclusion of the course as part of subsequent elective coursework. Examples of student project proposals are found in Table 2.
Module 1 consisted of an introduction to the themes and purpose of the leadership curriculum and how this curriculum would fit in with other IPPE coursework. To serve as a source of inspiration about the importance of leadership for the future of the profession, students had access to short videos of Rear Admiral Scott Giberson and the CEO of the American Pharmacists Association, Tom Menighan, that were created specifically for this curriculum. Students were required to reflect on the type of leaders and leadership traits that would be needed to transform the US health care system into one that meets the 


\section{American Journal of Pharmaceutical Education 2019; 83 (5) Article 6764.}

IHI's Triple Aim goals. This was accomplished through completing assignments that required responses to thought-provoking questions related to readings from $\mathrm{Im}$ proving Patient and Health System Outcomes through Advanced Pharmacy Practice: A Report to the US Surgeon General 20113 and High Impact Leadership: Improve Care, Improve the Health of Populations, and Reduce Costs. ${ }^{9}$ Students were introduced to the CCPP and community pharmacy practice partners. The CCPP guide had six main steps (https://communitypharmacyfoundation.org/grants/grants_list_details.asp?grants_id= 71006). The students were assigned staggered deadlines for completing different components of the project guide during the first three modules. Having these milestones and project deadlines helped to ensure that the students would complete the assignments in the project guide prior to the project pitch presentation.

During module 2, the relationship between leadership and change was emphasized. Students completed the CliftonStrengths (www.strengthsquest.com) talent assessment survey online to identify and understand their individual strengths. Upon completion of the assessment, the students independently answered reflective questions about personal strengths and how they could use their strengths for advancement. Additionally, students considered how their strengths could potentially be a liability. Students answered questions about which strengths they would most likely utilize within their team based on their personal top five themes.
Module 3 allowed students to explore how personal strengths impact team dynamics and influence organizational culture. Leslie Fox, BS, a health care policy and advocacy director for over 6 years with a Fortune 100 company and experience in the creatation of effective teams through strengths application, gave a presentation at both universities on how individual strengths create diversity in a team and make it more balanced and effective. Fox provided a real-world perspective by sharing examples of how strengths play a role in the organizational culture of her company. As a follow up to Fox's presentation, student pharmacists were asked to complete a team reflection about their strengths. The goal of this assignment was to help students think through their current team dynamics and how the team should modify roles and responsibilities during the rest of the curriculum to be most effective.

At this point, students had almost completed their project proposals, so in module 4, they were shown how to effectively pitch their idea to stakeholders. The students were taught how persuasively communicating an idea for a pharmacy service is different from giving a presentation on a topic, and how to structure their team's project pitch, which would be delivered as part of module 5. Students were provided with a project pitch guide and rubric to help them prepare.

For module 5, student teams delivered their fiveminute project pitch presentations live to classmates, teachers, and community pharmacy partners. All presentations were evaluated via a graded rubric in real time,

Table 2. Selected Community Pharmacy Project Ideas Submitted by Second-Year Pharmacy Students as Part of a Curriculum Designed to Develop Student Pharmacist Leadership and Entrepreneurial Skills in Addressing Unmet Patient Care Needs

\begin{tabular}{|c|c|c|c|}
\hline WSU Fall 2015 & WSU Fall 2016 & UW Fall 2015 & UW Fall 2016 \\
\hline $\begin{array}{l}\text { Basic diagnosis and } \\
\text { treatment for } \\
\text { uncomplicated } \\
\text { urinary tract } \\
\text { infections }\end{array}$ & $\begin{array}{l}\text { High-risk patient genetic testing } \\
\text { focusing on improving health } \\
\text { outcomes with drug dosing } \\
\text { adjustments and lifestyle } \\
\text { modifications }\end{array}$ & $\begin{array}{l}\text { Diabetes follow-up: New } \\
\text { insulin prescription } \\
\text { check-on }\end{array}$ & $\begin{array}{l}\text { Increase Tdap vaccination rate in } \\
\text { pregnant women }\end{array}$ \\
\hline $\begin{array}{l}\text { Rural preventative } \\
\text { health screenings }\end{array}$ & $\begin{array}{l}\text { Pain management service and } \\
\text { education focused on decreasing } \\
\text { inappropriate use associated with } \\
\text { narcotics }\end{array}$ & $\begin{array}{l}\text { Incorporating a pharmacist } \\
\text { on the interprofessional } \\
\text { team for managing } \\
\text { congestive heart failure }\end{array}$ & $\begin{array}{l}\text { Home visit service after major } \\
\text { surgical interventions }\end{array}$ \\
\hline & $\begin{array}{l}\text { Phone app that combines self-care, lab } \\
\text { values and medication adherence } \\
\text { functions intending to assist } \\
\text { patient's in holistically addressing } \\
\text { and tracking medical treatments } \\
\text { with drug and nondrug } \\
\text { interventions }\end{array}$ & & $\begin{array}{l}\text { Provide electronic resources through } \\
\text { a secure patient portal that includes } \\
\text { information on all of the patient's } \\
\text { prescription medications, } \\
\text { including pictures, dosing, and } \\
\text { links to standardized patient- } \\
\text { friendly information that is } \\
\text { commonly found on a patient } \\
\text { information leaflet and access to } \\
\text { medication guides. }\end{array}$ \\
\hline
\end{tabular}




\section{American Journal of Pharmaceutical Education 2019; 83 (5) Article 6764.}

but the presentations were also recorded. The panel members evaluating the project pitch presentations were encouraged to ask questions on material that was unclear and provide brief input regarding the feasibility of the project. Having community practice partners as part of the evaluating panel enhanced the authenticity of the experience for students. After completing the project pitch, students were asked to complete a team member evaluation. The team member evaluation asked students to reflect on and rate each team member's level of participation in, effort toward, and sense of responsibility about achieving team goals, including their own. This evaluation also provided an opportunity for students to provide feedback on how each team member's strengths contributed to teamwork.

We intentionally placed the CCPP and the leadership curriculum in the fall of the second-year pharmacy curriculum after students had completed the community introductory pharmacy practice experience (IPPE). The strategic placement in the core curriculum allowed for student pharmacists to draw from their community IPPE to help create their project proposal for their new or enhanced clinical service.

Throughout the course, a variety of assessments were used. One of the primary methods of assessment of the overall innovation was a pre-course assessment (Appendix 1), which students had to fill out prior to module 1, and a post-course assessment, which they filled out after module 5 (Appendix 2). All students were asked to complete the assessments as part of the course.

To gauge the overall impact of the experience, the students were asked a series of questions regarding their confidence in seven areas related to leading change. On the precourse assessment, students rated their confidence at that moment in time (ie, prior to the start of the course curriculum). On the postcourse assessment, students rated their confidence at the end of the course. To address potential concerns related to response-shift bias in selfreport measures ${ }^{10}$ students also completed a retrospective pretest measure at the end of the course in which they were asked to think back to the beginning of the course and rate how confident they had been before the start of the leadership curriculum. Because students' knowledge, understanding, and attitudes are likely to change during their educational experience, a retrospective pretest design was used to provide a more accurate assessment of change than a simple pretest-posttest approach would have provided. ${ }^{11,12}$

Students' mean scores were compared using paired sample $t$ tests for precourse and postcourse, retrospective and postcourse, and retrospective and precourse relationships. To control for inflation of type I error (which may have occurred due to 21 pairwise tests being performed using the same data set), a strict Bonferonni adjustment was applied. Because the curriculum was delivered asynchronously on two different campuses, the response means from the two student populations were also compared using Welch's $t$ test $(p<.05){ }^{13}$

\section{RESULTS}

The pre- and postcourse assessments were completed by students enrolled in the course at both campuses. Of the 465 total students enrolled (283 at WSU and 182 at UW), 404 students completed the both assessments (224 were at WSU and 180 at UW).

On the precourse assessment, students were asked to indicate if they had any prior experience with implementing a change or a new process, regardless of the setting (Table 3 ). Only $41 \%$ of students responded that they had any previous experience in this area. Of those reporting prior experience, $32 \%$ (13\% of all students surveyed) indicated the experience was pharmacy related.

Students demonstrated significant improvement in all seven confidence areas as determined by comparison of precourse and postcourse scores (Table 3). Similarly, significant improvement was found when students' scores on the retrospective assessment of confidence were compared with scores on the postcourse assessment in all seven areas. These findings indicate that students felt more confident in their ability to lead change at the end of the course than they did at the beginning. Significant differences in the mean precourse scores and retrospective scores suggest the presence of response shift bias, which may also indicate that students had a different level of understanding and attitude toward the subject matter at the end of the course than at the beginning. These trends were observed in the overall population as well as when looking specifically at those students who indicated prior experience in implementing change. While the data are presented here in aggregate to demonstrate the overall impact, similar significant differences were observed in both student populations. Additionally, no significant difference was observed between the responses of the two populations.

Students were also asked in the pre- and post-course assessments to indicate how important they believed it was to continue improving on their skills in leading change. While the mean (SD) response from the precourse assessment of 85.0 (1.75) decreased slightly to the postcourse assessment mean of 82.9 (1.8), the response had started high and the change that occurred was not significant ( $p=.11$ ).

On the postcourse assessment, students were asked to reflect on Kotter's process for Leading Change. ${ }^{4}$ 


\section{American Journal of Pharmaceutical Education 2019; 83 (5) Article 6764.}

Table 3. Change in Student Leadership Confidence Based on Precourse, Retrospective Pretest, and Postcourse Test Responses

\begin{tabular}{|c|c|c|c|c|c|c|}
\hline & \multicolumn{3}{|c|}{ Mean (SD) } & \multicolumn{3}{|c|}{ Paired Samples $t$ Tests ${ }^{\mathrm{c}}$} \\
\hline & Precourse & Retrospective & Postcourse & Pre and Post & Retro and Post & Pre and Retro \\
\hline Leading Change & $63.0(2.1)$ & $56.4(2.1)$ & $72.2(1.7)$ & $9.34^{\mathrm{a}}$ & $21.67^{\mathrm{a}}$ & $6.18^{a}$ \\
\hline $\begin{array}{l}\text { Identifying \& Describing } \\
\text { Personal Strengths }\end{array}$ & $73.1(2.0)$ & $64.1(1.9)$ & $80.4(1.5)$ & $8.25^{\mathrm{a}}$ & $20.43^{\mathrm{a}}$ & $8.39^{\mathrm{a}}$ \\
\hline $\begin{array}{l}\text { Identifying \& Fostering } \\
\text { Strengths in Others }\end{array}$ & $68.3(1.9)$ & $62.8(2.0)$ & $76.0(1.7)$ & $8.28^{\mathrm{a}}$ & $17.01^{\mathrm{a}}$ & $5.44^{\mathrm{a}}$ \\
\hline Identifying New Services & $60.3(2.0)$ & $55.6(2.2)$ & $73.1(1.6)$ & $13.21^{\mathrm{a}}$ & $20.64^{\mathrm{a}}$ & $4.15^{\mathrm{a}}$ \\
\hline Developing a Plan & $59.2(2.1)$ & $55.4(2.3)$ & $73.3(1.7)$ & $14.72^{\mathrm{a}}$ & $19.80^{\mathrm{a}}$ & $3.44^{\mathrm{b}}$ \\
\hline Implementation & $61.5(2.1)$ & $56.1(2.3)$ & $74.2(1.7)$ & $13.17^{\mathrm{a}}$ & $20.3^{\mathrm{a}}$ & $4.93^{\mathrm{a}}$ \\
\hline Creative Decision-making & $64.6(2.1)$ & $59.3(2.2)$ & $76.1(1.7)$ & $12.74^{\mathrm{a}}$ & $19.55^{\mathrm{a}}$ & $4.79^{\mathrm{a}}$ \\
\hline
\end{tabular}

Students were asked which of the areas they felt they had improved in since the beginning of the course and which areas they would say they felt comfortable applying in the community pharmacy setting. The areas of Kotter's Model of Change that students felt had improved the most and felt most comfortable applying to a community pharmacy setting were communicate decisions (improvement, $73 \%$; confidence, $75 \%$ ), create a vision (improvement, $64 \%$; confidence, $56 \%$ ), and form a guiding coalition (improvement, $54 \%$; confidence, $55 \%)^{4}$ (Table 4). Students who indicated a substantial shift in their overall confidence in leading change were asked to respond with the specific major drivers of any shift they experienced. A total of 309 students answered this question, with 32 responding none or not applicable. Of the other 277 respondents, the majority (56\%) cited the team Community Pharmacy Project as a major driver. Other common responses included learning about change $(26 \%)$ and their StrengthsQuest results $(20 \%)$.

\section{DISCUSSION}

The small percentage of student pharmacists that reported having previous experience with effecting change in a pharmacy context seemed to affirm the case for requiring this type of curriculum for all students. Less than $15 \%$ of the students in this study had practiced implementing change in the pharmacy setting prior to this course. The high numbers of students that had not have this type of experience previously confirms there is a need for all students to have learning opportunities around change management. This was achieved by embedding this five-module curriculum into the PharmD program. Upon completing the experience, students' assessment responses indicated that they had confidence in their ability to lead change. Many of the students attributed their increased confidence to collaborating on the team project. Completing other learning modules in the course, which involved students learning about the change process and determining their strengths, also played a role in some students' increased confidence.

The community pharmacy partners who participated with this project expressed enthusiasm for the quality and the creativity showcased during the project pitch. In a conversation with Jenny Arnold, director of practice development for the Washington State Pharmacy Association in October 2015, she said, "Having the students present their Leadership Projects in only five minutes gave them the challenge of refining their work down to

Table 4. Students' Reported Improvement and Confidence in Leading Based on Kotter's Process for Leading Change, N=420

\begin{tabular}{lcc}
\hline & Improvement (\%) & Confidence (\%) \\
\hline Create urgency & 29 & 38 \\
Form a guiding coalition (team) & 54 & 55 \\
Create a vision & 64 & 56 \\
Communicate decisions & 73 & 75 \\
Empower others to act on the vision & 49 & 52 \\
Create quick wins & 29 & 35 \\
Build on the change & 46 & 48 \\
Institutionalize the change & 23 & 24 \\
\hline
\end{tabular}




\section{American Journal of Pharmaceutical Education 2019; 83 (5) Article 6764.}

the essence, and presenting just the most important aspects. This is a great skill for any pharmacist to have when they want to promote something to leaders, their patients, or the community."

Beverly Schaefer, Clinical Professor and owner of Katterman's Sand Point Pharmacy, Seattle, Washington, a well-respected thought leader and innovator in community pharmacy practice shared in a debrief after the project pitch presentations at University of Washington in November 2015 "that all of the groups should receive an A for thinking outside of the box." Schaefer also stated that part of change agent creation results from not being limited by boundaries.

The UW and WSU collaborated to successfully design a curriculum focused on developing student pharmacist leadership and entrepreneurial skills. Having the collective expertise and pooled resources that this collaboration provided resulted in a better curricular model than either school could have achieved alone. The collaboration also ensured the curriculum could be delivered asynchronously in different curricular structures. The two schools differ in a variety of ways. The UW operates on the quarter system, where as WSU operates on the semester system. Classes for the IPPE course are held every other week at UW versus weekly at WSU. Additionally, the team sizes for the Community Pharmacy Project were different at each school because of logistical factors such as the different class sizes at the two schools, the length of each class period, and available classroom space. The successful implementation of this curriculum within two different curricular structures suggests its future transferability and adaptability to other curricular models.

Students indicated in course evaluations that they would have appreciated additional time to focus on their strengths and how strengths influence individual behavior and decision making. Giving consideration to how the identification and development of strengths could be woven throughout all years of the PharmD curriculum is a critical next step in further developing this leadership curriculum. Strengths could be incorporated into mentor meetings, projects in other courses, peer tutoring, career development, preceptor feedback during experiential education, etc. In the future, it would be advantageous to increase the number of leadership development opportunities across the curriculum in both curricular and cocurricular experiences. While there was a slight decrease in the mean response to the question about the need for students to continue improving their skills in leading change, this may have been due in part to the students having recently completed this curriculum. Further assessment of student perceptions in this area is needed after students have had more time to apply what they have learned and to identify focused areas for growth and improvement.

Time constraints also limited the type and frequency of feedback provided to the teams about their CCPP guide and subsequent project pitch. All students were provided with summative feedback with limited formative interactions throughout the project development phase. Although students were encouraged both inside and outside of class to ask questions and seek help in forming their project proposal, this opportunity was not taken advantage of by all groups. Increasing access to early guidance and mentoring with more formative feedback may have resulted in higher quality student project proposals and pitches.

\section{CONCLUSION}

According to Dr. Dee Fink when faculty "find a way to help students achieve one kind of learning, they can in fact, enhance, not decrease student achievement in other kinds of learning." " He also states that when all six kinds of learning are included in the course design, "significant learning" occurs. ${ }^{6}$

This leadership and project-based curriculum is an innovative model for helping students achieve Fink's significant learning by using "foundational knowledge" and concepts learned in the course (eg, Kotter's 8-Step Model for Leading Change ${ }^{4}$ and the IHI' Triple Aim goals ${ }^{2}$ ), which are then "applied" to address real challenges in the community setting (integration), resulting in students seeing the relevance and importance of their learning (caring). Completing StrengthsFinder,reflection assignments and receiving feedback from peers, faculty members, and community practitioners helped students also understand the critical role of interpersonal relationships and how they could be an effective leader, supportive team member (human dimension), and self-directed learner (learning how to learn).

While the impact of this innovation is encouraging, our results still need to be compared with other measures, such as project success, project sustainability, and subsequent assessments (eg, APPE evaluation forms and graduate, alumni, and employer surveys) to understand further the true significance of this learning.

\section{ACKNOWLEDGMENTS}

The authors thank the Community Pharmacy Foundation for the grant awarded and for their assistance, along with that of the Washington State Pharmacy Association, Leslie Fox, and the community pharmacy partners. The Community Pharmacy Foundation provided financial resources to support the development of the leadership curriculum and mini-grant funding to underwrite the implementation of select innovative student proposals. 


\section{American Journal of Pharmaceutical Education 2019; 83 (5) Article 6764.}

\section{REFERENCES}

1. Bradley-Baker LR, Murphy NL. Leadership development of student pharmacists. Am J Pharm Educ. 2013;77(10):Article 219. https://doi.org/10.5688/ajpe7710219.

2. Stiefel M, Nolan K. A guide to measuring the triple aim: population health, experience of care, and per capita cost. Institute for Healthcare Improvement. http://www.ihi.org/resources/Pages/ IHIWhitePapers/AGuidetoMeasuringTripleAim.aspx. Published 2012. Accessed June 4, 2019.

3. Giberson S, Yoder S, Lee MP. Improving Patient and Health System Outcomes through Advanced Pharmacy Practice: A Report to the U.S. Surgeon General. Office of the Chief Pharmacist. U.S. Public Health Service. December 2011.

4. Kotter JP. Leading change. Harvard Business Review Press. https://www.acpe-accredit.org/pdf/Standards 2016FINAL.pdf. Published 2012. Accessed June 26, 2016.

5. Fink. L. "What is 'Significant Learning'?" University of Oklahoma Significant Learning Website, Program for Instructional Innovation at the University of Oklahoma. https://

www.deefinkandassociates.com/GuidetoCourseDesignAug05.pdf. Published 2003. Accessed July 17, 2017.
6. Kolb DA. Experiential Learning: Experience as the Source of Learning and Development. Englewood Cliffs, NJ: Prentice-Hall. 1984. 7. Challenge based learning: A classroom guide. Apple. https:// images.apple.com/education/docs/CBL_Classroom_Guide_Jan_2011.pdf. Published 2011. Accessed June 4, 2019.

8. Swenson S, Pugh M, McMullan C, Kabecenell A. High impact leadership: improve care, improve the health of populations and reduce costs. Institute for Health Improvement. http://www.ihi.org/ resources/Pages/IHIWhitePapers/HighImpactLeadership.aspx. Published 2013. Accessed June 4, 2019.

9. Howard GS, Dailey PR. Response-shift bias: a source of contamination of self-report measures. J Appl Psyc. 1979;64:144-150. 10. Goedhart H, Hoogstraten J. The retrospective pretest and the role of pretest information in evaluation studies. Psyc Reports. 1992;70:699-704.

11. Howard GS, Schmeck RR, Bray JH. Internal invalidity in studies employing self-report instruments: a suggested remedy. $J E d$ Measurement. 1979;16(2):129-135.

12. Delacre M, Lakens D, Leys C. Why psychologists should by default use Welch's $t$-test instead of Student's $t$-test. Int Rev Soc Psychol. 2017;30(1):92-101. 


\section{American Journal of Pharmaceutical Education 2019; 83 (5) Article 6764.}

Appendix 1. Pre-Course Assessment

For scale-response questions, an 11-point scale from 0 to 100 offered in increments of 10 was used.

Provide your response to the following questions about leadership and change.

Explain the importance of leadership in pharmacy.

Have you had experience implementing change to an existing process or implementing something new? [Please note that your prior experience doesn't need to be pharmacy related.] Yes/No

If you answered yes to the previous question, please describe the experience.

How confident are you at leading change at this time? (scale)

How important is it to you to improve your skills in leading change? (scale)

Provide your response to the following questions about strengths.

If someone asked you to describe your personal strengths, what are 3 strengths that you would list?

How confident are you in your ability to identify and describe your personal strengths? (scale)

For each of the following questions, assume that you were asked to join a project that involves working with a team.

How would you describe the concept of a 'shared vision'?

What strategies might you employ to communicate goals and build consensus in a team setting?

How confident are you in your ability to foster team members' strengths? (scale)

For the following questions, assume that you have been asked to develop a project with a group of co-workers in the community pharmacy setting. The project requires you to plan for implementing a new service to the pharmacy or improve an existing service.

What factors should you consider in coming up with an idea for a new or enhanced service?

When developing a proposal for this project that you will present to pharmacy leadership, what key areas should you include in the outline? How would you plan to monitor if your group's project is successful and sustainable?

How confident are you in your ability to identify new services and approaches to improve existing care, the patient experience, or resource-utilization in the community pharmacy setting? (scale)

How confident do you feel developing a plan for a change to an existing process or in developing a new process/project? (scale)

How confident do you feel implementing a change to an existing process or in developing a new process/project? (scale)

How confident are you in your ability to demonstrate creative decision making when confronted with potential challenges or novel problems. (scale)

Appendix 2. Post Course Assessment

Provide your response to the following questions about leadership and change.

Explain the importance of leadership in pharmacy.

Post-Course only: Which areas of leading change have you improved since the beginning of this course? (Select all that apply) Create Urgency

Form a Guiding Coalition (team)

Create a Vision

Communicate Decisions

Empower others to act on the Vision

Create Quick Wins

Build on the Change

Institutionalize the Change Source: Kotter's 8 Steps of Change ${ }^{4}$

Post-Course only: Which of the following areas of leading change do you feel comfortable applying in the pharmacy practice setting? (Select all that apply)

Create Urgency

Form a Guiding Coalition (team)

Create a Vision

Communicate Decisions

Empower others to act on the Vision

Create Quick Wins

Build on the Change

Institutionalize the Change Source: Kotter's 8 Steps of Change ${ }^{4}$ 


\section{American Journal of Pharmaceutical Education 2019; 83 (5) Article 6764.}

How confident are you at leading change at this time? (scale)

Post Course Only: How confident were you in your ability to lead change at the beginning of the course? (scale)

Post Course Only: If there was a change in your confidence in your ability to lead change from the beginning to the end of the course, what were major drivers that influenced the change?

How important is it to you to improve your skills in leading change? (scale)

Provide your response to the following questions about strengths.

If someone asked you to describe your personal strengths, what are 3 strengths that you would list?

Knowing what you know now, how confident are you in your ability to identify and describe your personal strengths? (scale)

Post Course Only: Thinking back to the beginning of the course, how confident were you in your ability to identify and describe your personal strengths? (scale)

For each of the following questions, reflect on your work with your team in this course.

What strategies did you employ to communicate goals and build consensus in a team setting? What might you do differently in the future?

How did you use your strengths when working with a team? What might you do differently in the future?

How did you foster the strengths of your team members? What might you do differently in the future?

How successful do you feel you were in fostering team members' strengths? (scale)

Did your team encounter any major challenges in developing your project proposal? How did you work together to overcome them?

Thinking back to the beginning of the course, how confident were you in your ability to foster team members' strengths? (scale)

How confident are you in your ability to identify new services and approaches to improve existing care, the patient experience, or resource-utilization in the community pharmacy setting? (scale)

Thinking back to the beginning of the course, how confident were you in your ability to identify new services and approaches to improve existing care, the patient experience, or resource-utilization in the community pharmacy setting? (scale)

How confident do you feel developing a plan for a change to an existing process or in developing a new process/project? (scale)

Thinking back to the beginning of the course, how confident did you feel developing a plan for a change to an existing process or in developing a new process/project at the beginning of the course? (scale)

How confident do you feel implementing a change to an existing process or in developing a new process/project? (scale)

Thinking back to the beginning of the course, how confident did you feel implementing a change to an existing process or in developing a new process/project? (scale)

How confident are you in your ability to demonstrate creative decision making when confronted with potential challenges or novel problems? (scale)

Thinking back to the beginning of the course, how confident were you in your ability to demonstrate creative decision making when confronted with potential challenges or novel problems? (scale) 